\title{
Effects of nutrition motivational intervention in patients affected by type 2 diabetes mellitus: a longitudinal study in Naples, South Italy
}

\author{
Valeria Di Onofrio ${ }^{1 *} \mathbb{D}$, Francesca Gallé2, Mirella Di Dio², Patrizia Belfiore ${ }^{2}$ and Giorgio Liguori ${ }^{2}$
}

\begin{abstract}
Background: Type 2 diabetes (T2D) is associated with a prion diminished quality of life, especially due to the severe complications that it implicates. Changing dietary habits is an absolute priority, as well as implementing nutritional motivational programs. The aim of this study was to verify the effectiveness of a nutritional intervention in improving the health of patients affected by T2D.

Methods: A total of 69 patients participated in a nine-months motivational program focused on the principles of the Mediterranean diet, the classes of nutrients, the distribution of the meals during the day and the dietary choices. During regular meetings, the patients were requested to fill out a questionnaire about their dietary habits and behaviours. Clinical and metabolic parameters were also analysed.

Results: At the end of the intervention the number of people who declared that they ate five meals a day $(p=0.006)$ and preferred to have fruit for snack $(p=0.004)$ increased, while there was a reduction in the use of sweeteners and an elimination of the use of fructose $(p=0.05)$. The total daily consumption of kilocalories (kcal) had been reduced and the percentages of carbohydrates, proteins and lipids, after the intervention, follow the guidelines. In relation to this, a significant improvement $(p<0.05)$ was registered in systolic and diastolic pressure, BMI and waist circumference, as well as in glycaemic values $(p=0.018)$.
\end{abstract}

Conclusions: A nutritional motivational intervention may be useful in improving dietary habits and health status of patients with T2D. We hope that a similar intervention will be applied in Campania and in other Italian regions.

Trial registration: Registration number is ISRCTN1 1067689; date of registration: 10/09/2018. Retrospectively registered.

Keywords: Type 2 diabetes, Nutritional motivational intervention, Management of chronic diseases

\section{Background}

Diabetes is an important public health problem, one of four priority noncommunicable diseases (NCDs) targeted for action by world leaders. Both the number of cases and the prevalence of diabetes have been steadily increasing over the past few decades. The global prevalence (age-standardized) of diabetes has nearly doubled since 1980 , rising from 4.7 to $8.5 \%$ in the adult population. Separate global estimates of diabetes prevalence for

\footnotetext{
* Correspondence: valeria.dionofrio@uniparthenope.it

${ }^{1}$ Department of Sciences and Technologies, University of Naples

"Parthenope", Business District, Block C4, 80143 Naples, Italy

Full list of author information is available at the end of the article
}

type 1 and type 2 do not exist. The majority of people with diabetes are affected by type 2 diabetes (T2D). The occurrence used to be almost entirely among adults, but now it occurs in children too [1-3].

In recent decades the prevalence of $\mathrm{T} 2 \mathrm{D}$ has increased worldwide, with values higher than $5 \%$ in Italy $[4,5]$.

T2DM is associated with a diminished quality of life, especially due to the severe complications that it implicates, leading to possible reductions in life expectancy of up to 10 years $[6,7]$.

Diabetes prevention and control may be influenced by behavioral factors such as diet and physical activity (PA).

(c) The Author(s). 2018 Open Access This article is distributed under the terms of the Creative Commons Attribution 4.0 International License (http://creativecommons.org/licenses/by/4.0/), which permits unrestricted use, distribution, and reproduction in any medium, provided you give appropriate credit to the original author(s) and the source, provide a link to the Creative Commons license, and indicate if changes were made. The Creative Commons Public Domain Dedication waiver (http://creativecommons.org/publicdomain/zero/1.0/) applies to the data made available in this article, unless otherwise stated. 
A healthful eating pattern is one of the key components of diabetes management [8].

The importance of interventions for Education and Promotion of Health is also emphasised by the Italian National Prevention Plan 2014-2018, which puts diabetes among the priorities of the National Health Service (http://www.salute.gov.it/imgs/C_17_pubblicazioni _2285_allegato.pdf).

Several studies show that motivational nutrition programs and training for patients with T2D can lead to health benefits (weight reduction, decreased cardiovascular risk and improved physical function) especially when these interventions include a cognitive-behavioral approach [9-16].

Many trials report that a balanced diet, body weight maintenance and regular exercise reduce the risk of T2D progression by $30-60 \%$ in people with impaired glucose tolerance [17-19].

Salas-Salvadó J et al. assert that the Mediterranean diet improves glucose homeostasis, measurable as a reduction in glycemia and glycosylated hemoglobin, and reduces by $30 \%$ the probability of developing T2D [20].

It is a priority to intervene on eating habits, implementing nutritional motivational programs. As also recommended by the guidelines for the treatment and management of diabetes [21], it would be ideal to implement an interdisciplinary intervention to inform people affected by the disease about the principles of a healthy diet and its benefits [22, 23].

In Italy, the use of the group care model, which is based on a clinical-educational approach, seems to be cost-effective and successful in improving diabetes management and quality of life in patients with T2D [24-26]. However, the use of therapeutic education for these patients in clinical practice encounters difficulties mainly due to the lack of facilities destined to this activity, and to the scarcity of trained operators [27].

We performed a study to verify the feasibility and efficacy of a nutritional motivational intervention in improving the health and disease self-management of patients affected by T2D in Naples, South Italy.

\section{Method}

This study is part of a health promotion intervention sponsored by the National Center for Prevention and Control of Diseases of the Italian Ministry of Health. It aimed to evaluate possible changes in food habits and health perception in a sample of individuals with T2D before and after a 9 month nutritional motivational program. Anthropometric parameters (BMI, waist measurement, hip measurement) and endocrinal-metabolic data (blood pressure, heart rate, glycaemia, HbA1c, total cholesterol, HDL, LDL, triglycerides, creatinine) were assessed before and after the intervention. Dietary habits were also evaluated. The investigation wasn't experimental, therefore a trial registration was not provided.

\section{Participants and setting}

In the preliminary phase of the study ( 3 months), physicians and diabeticians identified patients who were eligible and invited them to participate in the investigation. Eligibility criteria were being between 50 and 70 years old, living in the community, having been diagnosed with T2D at least 1 year prior, absence of major complications of diabetes. All participants were informed about the purpose of the study and the use of resulting data, and signed an informed consent for being included in the intervention. Participants joined the study groups on a voluntary basis.

Individuals who decided to take part in the nutritional motivational program formed the intervention group (IG) while recruited patients who decided not to follow the program were included in the control group (CG).

\section{Intervention}

The intervention lasted 9 months. The nutritional program was structured in quarterly group meetings conducted by a trained nutritionist, who discussed with patients the role of diet in diabetes control, Mediterranean diet benefits, healthy food choices, and how to manage their own nutrition through an adequate daily distribution of meals, using photo books containing examples of meals, as well as to learn a correct interpretation of food labels. Detailed information about how to prevent and manage hypoglycemia was given.

All procedures followed were in accordance with the ethical standards of the Responsible Committee on $\mathrm{Hu}$ man Experimentation (institutional and national) and with the Helsinki Declaration of 1975, as revised in 2008. Anonymity of personal data was guaranteed. All participants signed an informed consent form. For ethical reasons, all the participants in the control group received information about the principles of a healthy diet from their physicians. The study protocol was approved by the National Centre for the Prevention and Control of Disease (CCM).

\section{Outcomes}

This intervention aimed to promote the well-being of patients, involving and making them aware of their dietary choices. During the program some tools were provided to control body weight and maintain glucose homeostasis.

Dietary habits and behaviours, anthropometric and endocrinal-metabolic parameters, were assessed before (t0) and at the end ( $\mathrm{t} 3$ ) of the activities in participants to study the effects of the intervention.

During the periodical meetings, a questionnaire of 29 questions on dietary habits and behaviours previously 
validated in another intervention granted by the $\mathrm{Na}$ tional Center for Prevention and Control of Diseases of the Italian Ministry of Health [28] was carried out (see Additional file 1). This tool enabled the analysis of the daily consumption and type of foods eaten at breakfast, or as snacks, at lunch and dinner.

The average daily amount, average daily calories consumed, distribution into micro and macro nutrients and caloric breakdown between meals during the day were assessed and compared for each patient according to the dietary anamnesis software $\mathrm{WinFood}^{\circ}$ (Medimatica S.u.r.l. - Teramo, Italy).

\section{Statistical analysis}

The answers to the questionnaires on dietary habits and behaviours of the IG and the CG, at the start and the end of the program, were analysed using the $X^{2}$ test.

The Student $t$ test and variance analysis (ANOVA) were applied for the comparison of endocrinal-metabolic parameters (and their variations) between the IG and the CG at the start (t0) and end (t3) of the intervention. A $p$ value of 0.05 was considered as the level of significance. All the analyses were carried out using IBM SPSS statistics version 23 for Windows (SPSS, Chicago, IL, USA).

\section{Results}

Participation and socio-demographic characteristics of the participants

Out of the 213 subjects who accepted to participate in the study, 69 (32.4\%) completed the program $(\mathrm{IG}=47 \mathrm{M}$ and 22F; mean age $64 \pm 5.57)$ and 210 controls who participated in the follow-up (CG $=108 \mathrm{M}$ and $102 \mathrm{~F}$; mean age $65 \pm 7.46$ ) were included in the final analysis.

Table 1 shows the socio-demographic characteristics of the two groups.

\section{Questionnaire on dietary habits and behaviours}

Table 2 shows the answers with statistically significant differences between $\mathrm{t} 0$ and $\mathrm{t} 3$ in IG patients; no statistical relevance was found among the CG responses (an additional file is more detailed (see Additional file 1).

In particular, there was a reduction in the consumption of white sugar and an increase of brown sugar; the fructose was eliminated $(p=0.05)$ and the consumption of five meals a day became deeply rooted $(p=0.006)$. Having fruit for snack doubled $(p=0.004)$ and there was an increase in the regular consumption of fish $(\mathrm{p}=0.004)$.

The ice cream consumption was halved and the patients preferred low-calorie drinks such as freshly-squeezed orange and ice lollies $(p=0.02)$.

The outcomes show that the habit of having breakfast, already high at t0 (95.7\%), improved significantly (100\%) $(p=0.08)$. The seasonal fruits and vegetables consumption
Table 1 Socio-demographic characteristics of the Intervention Group (IG) and of the Control Group (CG)

\begin{tabular}{|c|c|c|c|c|}
\hline \multirow[t]{2}{*}{ Variables } & \multicolumn{2}{|l|}{ IG } & \multicolumn{2}{|l|}{ CG } \\
\hline & N. & $\%$ & N. & $\%$ \\
\hline Age & $64 \pm 5.57$ & & $65 \pm 7.46$ & \\
\hline \multicolumn{5}{|l|}{ Gender } \\
\hline Males & 47 & 68.1 & 108 & 51.4 \\
\hline Females & 22 & 31.9 & 102 & 48.6 \\
\hline \multicolumn{5}{|l|}{ Educational qualifications } \\
\hline None & 1 & 1.5 & 16 & 7.6 \\
\hline Primary school & 16 & 23.2 & 64 & 30.5 \\
\hline Middle school & 22 & 31.9 & 24 & 11.4 \\
\hline High school diploma & 23 & 33.3 & 72 & 34.3 \\
\hline University degree & 5 & 7.2 & 24 & 11.4 \\
\hline No answer & 2 & 2.9 & 10 & 4.8 \\
\hline \multicolumn{5}{|l|}{ Occupation } \\
\hline Unemployed & 3 & 4.3 & 6 & 2.8 \\
\hline Housewife & 18 & 26.1 & 54 & 25.7 \\
\hline Pensioner & 29 & 42.0 & 34 & 16.2 \\
\hline Tradesman & 5 & 7.2 & 24 & 11.4 \\
\hline Office worker & 9 & 13.1 & 72 & 34.3 \\
\hline Self-employed & 4 & 5.8 & 10 & 4.8 \\
\hline No answer & 1 & 1.5 & 10 & 4.8 \\
\hline
\end{tabular}

increased $(p=1.48)$, while meat consumption decreased $(p=0.32)$, as that of cured meats, cheeses and bakery products containing oil and lard; there was a reduction in simple sugars intake in the form of sweets and candies and also in alcohol consumption outside the meal $(p=$ 1.82) (data not show).

The results of WinFood $7^{\circ}$ related to the dietary consumption of the IG are shown, at $\mathrm{t} 0$ and $\mathrm{t} 3$, in Table 3.

The total kcal were reduced, while the fibre intake stayed almost identical, below the recommended level [21]. The macronutrients distribution, carbohydrates percentages, protein and fats at $\mathrm{t} 3$ comply with guidelines. The relationship between starch and simple carbohydrates (in favour of the latter at $\mathrm{t} 0$ ) is more balanced at $\mathrm{t} 3$, but not optimal; there was a considerable reduction of saturated fats.

The calories distribution between meals after 9 months is closer to that recommended for a balanced diet.

There were no significant changes between $\mathrm{t} 0$ and $\mathrm{t} 3$ in the CG (data not show).

\section{Anthropometric and endocrinal-metabolic parameters}

After 9 months, the anthropometric and endocrinalmetabolic parameters in the IG had all improved. The parameters of this group are always better than those found in the CG (Table 4). 
Table 2 Main dietary habits and behaviours of the Intervention Group (IG) and the Control Group (CG) at t0 and t3

\begin{tabular}{|c|c|c|c|c|c|c|c|c|c|c|}
\hline \multirow{3}{*}{ Questions } & \multicolumn{5}{|l|}{ IG } & \multicolumn{5}{|l|}{ CG } \\
\hline & \multicolumn{2}{|l|}{ to } & \multicolumn{2}{|l|}{ t3 } & \multirow{2}{*}{$\begin{array}{l}x^{2} \\
\text { (p) }\end{array}$} & \multicolumn{2}{|l|}{ t0 } & \multicolumn{2}{|l|}{ t3 } & \multirow{2}{*}{$\begin{array}{l}x^{2} \\
\text { (p) }\end{array}$} \\
\hline & N. & $\%$ & N. & $\%$ & & N. & $\%$ & $\mathrm{~N}$ & $\%$ & \\
\hline \multicolumn{11}{|l|}{ What do you use to sweeten food and drinks? } \\
\hline White sugar & 25 & 36.2 & 23 & 33.3 & 0.05 & 73 & 34.8 & 68 & 32.4 & 0.85 \\
\hline Brown sugar & 7 & 10.2 & 13 & 18.8 & & 18 & 8.5 & 21 & 10.0 & \\
\hline Fructose & 7 & 10.2 & 0 & - & & 21 & 10.0 & 17 & 8.1 & \\
\hline Miele & 0 & - & 2 & 2.9 & & 3 & 1.4 & 5 & 2.4 & \\
\hline Sweeteners & 13 & 18.8 & 12 & 17.4 & & 41 & 19.6 & 48 & 22.8 & \\
\hline Nothing & 17 & 24.6 & 19 & 27.6 & & 54 & 25.7 & 51 & 24.3 & \\
\hline \multicolumn{11}{|l|}{ Do you eat five meals a day? } \\
\hline Yes & 30 & 46.4 & 46 & 66.7 & 0.006 & 91 & 42.3 & 100 & 47.6 & 0.38 \\
\hline No & 39 & 53.6 & 23 & 33.3 & & 119 & 57.7 & 110 & 52.4 & \\
\hline \multicolumn{11}{|l|}{ Do you snack on fruit? } \\
\hline Yes & 16 & 23.2 & 32 & 46.4 & 0.004 & 71 & 33.8 & 78 & 37.1 & 0.48 \\
\hline No & 53 & 76.8 & 37 & 53.6 & & 139 & 66.2 & 132 & 62.9 & \\
\hline \multicolumn{11}{|l|}{ Do you regularly eat fish? } \\
\hline Yes & 50 & 72.4 & 63 & 91.3 & 0.004 & 188 & 89.5 & 191 & 90.9 & 0.62 \\
\hline No & 19 & 27.6 & 6 & 8.7 & & 22 & 10.5 & 19 & 9.1 & \\
\hline \multicolumn{11}{|l|}{ What do you usually order at a coffee shop? } \\
\hline Bitter orangeade & 26 & 37.8 & 17 & 24.6 & 0.02 & 71 & 33.8 & 75 & 35.7 & 0.95 \\
\hline Freshly squeezed orange juice without sugar & 29 & 42.0 & 41 & 59.4 & & 115 & 54.8 & 112 & 53.3 & \\
\hline Ice lolly & 0 & - & 4 & 5.8 & & 18 & 8.6 & 16 & 7.7 & \\
\hline Ice cream cone & 14 & 20.2 & 7 & 10.2 & & 6 & 2.8 & 7 & 3.3 & \\
\hline
\end{tabular}

At the time of enrolment, the members of both groups presented an average BMI which placed them in the primary obesity band (IG $31.26 \pm 9.47$; CG $33.35 \pm 11.4$ ). At the end of the program, the average BMI in both groups seems generally reduced, only those in the IG fall within the overweight band $(26.85 \pm 2.74 ; p=0.01)$.

The average waist measurement at $t 0$, in men and women in the IG and the CG, was above the threshold values set by the WHO $(80 \mathrm{~cm}$ for women and $94 \mathrm{~cm}$ for men). At $\mathrm{t} 3$, these average values are reduced in both sexes and in both groups, but only the men in the IG fall within the values recommended by the WHO $(p=0.00)$.

In the CG there were no significant differences in endocrinal-metabolic parameter between the start and the end of the program, unlike the IG $(p \leq 0.05$ for BMI, glycaemia, waist measurement, systolic and diastolic pressure). The ANOVA test results show significant differences in parameters between the IG and CG.

\section{Discussion}

The increasing prevalence of T2D makes necessary and urgent to intervene on people's lifestyles, focusing mainly on a balanced diet and movement [29, 30]. Many studies suggest that eating a Mediterranean diet coincides with a reduced incidence of T2D [31-33].

The nutritional education that aims to correct and conscious food choices, associated with the active lifestyle promotion, can provide a renewed and complete therapeutic approach. It is able to offer patients highly effective tools to control the disease and improve the quality of life.

The main findings of this study are that a nine-month community-based nutritional motivational program improves dietary habits and behaviours, anthropometric and endocrinal-metabolic parameters in middle-aged and older subjects with T2D compared to control diabetic subjects undergoing only training about healthy style controlled by physicians and diabeticians. Although they did not join the program randomly but on a voluntary basis, two samples came out from the same population and were similar in age and sex.

The better received messages:

$\checkmark$ the fructose has a great hyper-triglyceridemising power. It was completely eliminated from the diet at the end of the program; 
Table 3 Results of WinFood7 ${ }^{\oplus}$ at t0 and t3 in relation to the food consumption of the IG

\begin{tabular}{llll}
\hline & & Average (t0) & Average (t3) \\
\hline LIST OF COMPONENTS & & & \\
Calories & Kcal & 2152.88 & 1588.04 \\
Alcohol & Kcal & 103.18 & 92.40 \\
Protein & $\mathrm{g}$ & 119.07 & 73.22 \\
Lipids & $\mathrm{g}$ & 100.83 & 49.83 \\
Glycids available & $\mathrm{g}$ & 176.94 & 199.83 \\
Starch & $\mathrm{g}$ & 48.15 & 67.61 \\
Oligosaccharides & $\mathrm{g}$ & 90.91 & 92.71 \\
Total fibre & $\mathrm{g}$ & 20.78 & 21.84 \\
Cholesterol & $\mathrm{mg}$ & 954.21 & 359.70 \\
Saturated fatty acids & $\mathrm{g}$ & 34.17 & 15.61 \\
Polyunsaturated fatty acids & $\mathrm{g}$ & 9.35 & 5.23 \\
Monounsaturated fatty acids & $\mathrm{g}$ & 49.02 & 25.58 \\
Calcium & $\mathrm{mg}$ & 1379.68 & 897.76 \\
Sodium & $\mathrm{mg}$ & 2794.45 & 1252.95 \\
Potassium & $\mathrm{mg}$ & 4207.25 & 3872.02 \\
\% BREAKDOWN AMONG MEALS (calories) & & \\
Breakfast & $\%$ & 29.40 & 18.26 \\
Snacks & $\%$ & 22.08 & 18.12 \\
Lunch & $\%$ & 29.84 & 36.86 \\
Dinner & 18.68 & 26.77 \\
\hline
\end{tabular}

$\checkmark$ it is necessary to eat 5 meals a day to maintain glycidic homeostasis;

$\checkmark$ it is necessary to abandon sugary drinks, seriously implicated in the dynamics of the disease, as reported by various studies [34-36].
Participants improved the ratio of simple vs complex carbohydrates and the content of fibre in their diet, despite not yet complying with optimal values.

A considerable reduction in daily caloric consumption was also found, with a total $50 \%$ reduction in levels of cholesterol and fatty acids at $\mathrm{t} 0$, with remarkable effects, similar to those related to carbohydrates, on the progression of disease and appearance of complications [37, 38].

The reduced intake of fatty acids in favour of unsaturated fatty acids, after 9 months, is related to the reduced consumption of meat, especially processed products, indicated in the questionnaire [39], and to the increased consumption of fish.

Over the 9 months, the average BMI in the IG passed from level one obesity to overweight values. This parameter, which did not change in the CG, seems to be the most significant indication of the success of the intervention.

Another important result is the waist measurement index found at $\mathrm{t} 3$ in the women in the IG which, despite being diminished, does not fall within the thresholds indicated by the WHO. We should remember that the mean age of participants, almost all of whom were post-menopausal, implies that the distribution of body fat is altered, and that it deposits mainly in the abdominal area. Another reason for these results is that basal metabolic values are lower in women than in men, and this makes more difficult to lose abdominal fat.

The relationships with the professionals and their communication skills, as well as the organization and the contents of the sessions were generally appreciated by the participants.

The main limitations of this study are related to the participation of patients. In particular, the poor adherence to

Table 4 Intra-group and inter-group comparison of clinical-metabolic parameters at t0 and t3 with relative $p$ values

\begin{tabular}{|c|c|c|c|c|c|c|c|c|c|c|c|}
\hline & \multicolumn{5}{|l|}{ IG } & \multicolumn{5}{|l|}{ CG } & \multirow{3}{*}{$\begin{array}{l}\text { ANOVA } \\
P\end{array}$} \\
\hline & \multicolumn{2}{|l|}{$t_{0}$} & \multicolumn{2}{|l|}{$t_{3}$} & \multirow{2}{*}{$\begin{array}{l}\text { t Student } \\
\text { P }\end{array}$} & \multicolumn{2}{|l|}{$t_{0}$} & \multicolumn{2}{|l|}{$t_{3}$} & \multirow{2}{*}{$\begin{array}{l}\text { t Student } \\
\mathrm{P}\end{array}$} & \\
\hline & average & $\sigma$ & average & $\sigma$ & & average & $\sigma$ & average & $\sigma$ & & \\
\hline $\mathrm{BMI}$ & 31.26 & 9.47 & 26.85 & 2.74 & $0.01^{*}$ & 33.35 & 11.14 & 30.57 & 4.23 & 0.3 & $0.045^{*}$ \\
\hline \multicolumn{12}{|c|}{ Waist measurement (cm) } \\
\hline Women & 100.33 & 14.03 & 94.00 & 17.04 & 0.49 & 109.2 & 7.46 & 105.2 & 5.26 & 0.35 & 0.33 \\
\hline Men & 106.46 & 11.94 & 90.37 & 10.70 & $0.00^{*}$ & 94.33 & 16.74 & 92.16 & 11.66 & 0.78 & $0.03^{*}$ \\
\hline Systolic pressure & 133.86 & 13.35 & 125 & 13.8 & $0.04^{*}$ & 136.42 & 11.99 & 133.07 & 10.31 & 0.44 & $0.001^{*}$ \\
\hline Diastolic pressure & 77.5 & 9.4 & 71 & 6.2 & $0.03^{*}$ & 75.71 & 9.3 & 76.53 & 6.2 & 0.79 & $0.001^{*}$ \\
\hline Glycaemia (mg/dl) & 145.2 & 39.94 & 119.23 & 19.2 & $0.018^{*}$ & 150.37 & 80.86 & 136 & 23.16 & 0.49 & $0.007^{*}$ \\
\hline $\mathrm{HbA1c}(\%)$ & 6.6 & 0.87 & 6.2 & 0.68 & 0.22 & 7.02 & 1.81 & 14.12 & 19.16 & 0.12 & $0.00^{*}$ \\
\hline Tot. chol. (mg/dl) & 176.26 & 41.91 & 177.34 & 24.71 & 0.9 & 185 & 44.34 & 181 & 42.23 & 0.79 & $0.00^{*}$ \\
\hline $\mathrm{HDL}(\mathrm{mg} / \mathrm{dl})$ & 49 & 9.2 & 52 & 12 & 0.5 & 52.11 & 11.37 & 49.33 & 11.11 & 0.48 & $0.00^{*}$ \\
\hline Triglycerides (mg/dl) & 172.34 & 78 & 131.86 & 66.9 & 0.1 & 142.6 & 62.05 & 155.46 & 85.18 & 0.62 & 0.5 \\
\hline Creatinine (mg/dl) & 6.2 & 23 & 2.6 & 2.58 & 0.57 & 3.23 & 2.8 & 3.35 & 2.99 & 0.91 & 0.3 \\
\hline
\end{tabular}


the study reflects a lack of acceptance of similar interventions to promote healthy lifestyle in the population considered. Furthermore, the considerable number of dropouts and withdrawals observed among study participants should be considered. Although we have not thoroughly investigated the reasons for dropouts, this could be related to the type of supportive patients received from the staff of these facilities. However, the levels of neglect recorded in this study are comparable to those reported by other similar studies [40-42].

The lack of randomization is another important limit: one would expect that those who were not willing to participate in the motivational program were less motivated to improve their health. However, the improvement of most parameters reported by the controls suggest that the effect of this possible distortion was minimal.

Finally, it should be noted that our intervention involved only individuals aged 50 to 70 , while in Italy the highest age group affected by diabetes is that of the elderly aged $\geq 75$ (prevalence rate $19.8 \%$ ) [5].

In conclusion, a community-based long-term intervention that includes a supervised food motivational program can improve the health of individuals with T2D.

The main criticality found was the significant loss of participants at the follow-up; as already mentioned, only $36.3 \%$ of those who started out completed the whole nine-month program.

The reasons for such an important drop-out can be attributed to a lack of commitment at the time of enrolment and of motivation of doctors, insufficient support from expert educators or logistic difficulties, due to family/personal problems which are not always easy to define and solve.

Changes in the anthropomorphic and endocrinal-metabolic parameters found among participants in the activities highlighted the effectiveness of the intervention described, configuring it as a valid form of tertiary prevention transferrable at territorial level.

\section{Conclusions}

The structured intervention turned out to be feasible in the Neapolitan community: it was appreciated by participants and did not require great amounts of personnel or economic resources. As reported in a previous economic analysis, an exercise-based intervention for diabetic subjects could represent a cost-saving strategy for diabetes management, especially for complicated cases [43]. Therefore, the proposed intervention could be considered as an effective and inexpensive tool to improve health and prevent complications in subjects with T2D.

The active involvement and interconnection between the various figures involved (doctors, educators) is decisive in accompanying and actively sustaining patients in the adoption of a more active and healthy life style; this is an element on which it is necessary to insist because a lack of compliance turned out to be the most significant criticality.

Training in health education aimed at healthcare professionals could help reduce the drop-out.

It is evident that the intervention cannot be implemented without a network of collaborators where various components operate synergistically and with equal efficiency, with a view to achieving shared aims.

The involvement of institutions, able to give priority to public health, is the strength of the project. it aims to underline the prevention importance and health promotion in improving the quality of life of diabetic patients.

The patient's care must go through the remodulation of the ATDP (Assistance-treatment-diagnostic protocol) that includes appropriate interventions for promotion and education in health, through correct dietary choices and an active life.

Considering the positive aspects of the project, we hope that this model, with the appropriate improvements, can continue to be applied and extended to other areas and to the management of other chronic situations.

\section{Additional file}

Additional file 1: Questionnaire on dietary habits and behaviours. Questionnaire of 29 questions on dietary habits and behaviours previously validated in another intervention granted by the National Center for Prevention and Control of Diseases of the Italian Ministry of Health. (DOC $114 \mathrm{~kb}$ )

\section{Abbreviations}

BMI: Body Mass Index; CCM: National Centre for the Prevention and Control of Disease; CG: Control group; GP: General Practitioners; HbA1c: Glycated haemoglobin; HDL: High-Density Lipoprotein; IG: Intervention group; LDL: Low-density Lipoprotein; T2D: Type 2 diabetes; WHO: World Health Organization

\section{Acknowledgments}

The authors were supported by the National Center for Prevention and Control of Diseases of the Italian Ministry of Health. The authors thank the physicians, the diabeticians, and the patients who participated to the study.

\section{Funding}

This study was funded by the National Center for Prevention and Control of Diseases of the Italian Ministry of Health (CCM funding, 2012) and by the University of Naples Parthenope (funding for competitive research, 2016).

\section{Availability of data and materials}

The dataset supporting the conclusions of this article is included within the article.

\section{Authors' contributions}

VDO carried out the data analysis, wrote and drafted the manuscript. GL was instrumental in designing the study. FG and MDD played primary roles in acquiring the data, overseeing statistical analyses and drafting the manuscript. PB participated in the study's design and coordination. All authors read and approved the final manuscript. 


\section{Ethics approval and consent to participate}

All procedures followed were in accordance with the ethical standards of the responsible committee on human experimentation (institutional and national) and with the Helsinki Declaration of 1975, as revised in 2008. Anonymity of personal data was guaranteed. All participants signed an informed consent form. For ethical reasons, all the participants in the control group received information about the principles of a healthy diet from their physicians. The study protocol was approved by the National Centre for the Prevention and Control of Disease (CCM).

\section{Consent for publication}

Not applicable.

\section{Competing interests}

All authors declare that they have no competing interests.

\section{Publisher's Note}

Springer Nature remains neutral with regard to jurisdictional claims in published maps and institutional affiliations.

\section{Author details}

${ }^{1}$ Department of Sciences and Technologies, University of Naples "Parthenope", Business District, Block C4, 80143 Naples, Italy. ${ }^{2}$ Department of Movement and Wellbeing Sciences, University of Naples "Parthenope", Via Medina 40, 80133 Naples, Italy.

\section{Received: 8 January 2018 Accepted: 5 October 2018}

Published online: 17 October 2018

\section{References}

1. World Health Organization. Global report on diabetes. Geneva: WHO; 2016

2. Wild S, Roglic G, Green A, Sicree R, King H. Global prevalence of diabetes: estimates for the year 2000 and projections for 2030. Diabetes Care. 2004; 27:1047-53.

3. Shaw JE, Sicree RA, Zimmet PZ. Global estimates of the prevalence of diabetes for 2010 and 2030. Diabetes Res Clin Pract. 2010:87:4-14.

4. World Health Organization. Noncommunicable diseases progress monitor 2017. Geneva: WHO; 2017.

5. Italian Institute of Statistics. Indagine Multiscopo "Aspetti della vita quotidiana". 2016.

6. Roper NA, Bilous RW, Kelly WF, Unwin NC, Connolly VM. Excess mortality in a population with diabetes and the impact ofmaterial deprivation: longitudinal, population based study. BMJ. 2001;322(7299):1389-93.

7. Gregg EW, Gu Q, Cheng YJ, Narayan KM, Cowie CC. Mortality trends in men and women with diabetes, 1971 to 2000. Ann Intern Med. 2007;147(3):14955.

8. Evert $A B$, Boucher $J$, Cypress $M$, et al. Nutrition therapy recommendations for the management of adults with diabetes. Diabetes Care. 2013;36(11): 3821-42.

9. Dunstan DW, Daly RM, Owen N, et al. High-intensity resistance training improves glycemic control in older patients with type 2 diabetes. Diabetes Care. 2002;25(10):1729-36.

10. Goldhaber-Fiebert JD, Goldhaber-Fiebert SN, Tristán ML, Nathan DM. Randomized controlled community-based nutrition and exercise intervention improves glycemia and cardiovascular risk factors in type 2 diabetic patients in rural Costa Rica. Diabetes Care. 2003;26(1):24-9.

11. Klein S, Sheard NF, Pi-Sunyer X, et al. Weight management through lifestyle modification for the prevention and management of type 2 diabetes: rationale and strategies: a statement of the American Diabetes Association, the north American Association for the Study of obesity, and the American Society for Clinical Nutrition. Diabetes Care. 2004;27(8):2067-73.

12. Dunstan DW, Daly RM, Owen N, et al. Home-based resistance training is not sufficient to maintain improved glycemic control following supervised training in older individuals with type 2 diabetes. Diabetes Care. 2005;28(1):3-9.

13. Dunstan DW, Vulikh E, Owen N, Jolley D, Shaw J, Zimmet P. Community center-based resistance training for the maintenance of glycemic control in adults with type 2 diabetes. Diabetes Care. 2006:29(12):2586-91.

14. Huang XL, Pan JH, Chen D, Chen J, Chen F, Hu TT. Efficacy of lifestyle interventions in patients with type 2 diabetes: a systematic review and meta-analysis. Eur J Intern Med. 2016;27:37-47.
15. Look AHEAD Research Group, Wing RR. Long-term effects of a lifestyle intervention on weight and cardiovascular risk factors in individuals with type 2 diabetes mellitus: four-year results of the Look AHEAD trial. Arch Intern Med. 2010;170(17):1566-75.

16. Minges KE, Cormick G, Unglik E, Dunstan DW. Evaluation of a resistance training program for adults with or at risk of developing diabetes: an effectiveness study in a community setting. Int J Behav Nutr Phys Act. 2011:8:50.

17. Gillies $\mathrm{CL}$, Abrams KR, Lambert PC, et al. Pharmacological and lifestyle interventions to prevent or delay type 2 diabetes in people with impaired glucose tolerance: systematic review and meta-analysis. BMJ. 2007;334(7588):299.

18. Stevens JW, Khunti K, Harvey R, Johnson M, Preston L, Woods HB, Davies M, Goyder E. Preventing the progression to type 2 diabetes mellitus in adults at high risk: a systematic review and network meta-analysis of lifestyle, pharmacological and surgical interventions. Diabetes Res Clin Pract. 2015; 107(3):320-31

19. Yoon U, Kwok LL, Magkidis A. Efficacy of lifestyle interventions in reducing diabetes incidence in patients with impaired glucose tolerance: a systematic review of randomized controlled trials. Metabolism. 2013;62(2):303-14.

20. Salas-Salvadó J, Guasch-Ferré M, Lee CH, Estruch R, Clish CB, Ros E. Protective effects of the Mediterranean diet on type 2 diabetes and metabolic syndrome. J Nutr. 2016;146(4):920S-7S.

21. AMD- SID. Standard Italiani per la cura del diabete mellito. Edizione 2016.

22. Ley SH, Hamdy O, Mohan V, Hu FB. Prevention and management of type 2 diabetes: dietary components and nutritional strategies. Lancet. 2014; 383(9933):1999-2007.

23. England CY, Thompson JL, Jago R, Cooper AR, Andrews RC. Dietary changes and associations with metabolic improvements in adults with type 2 diabetes during a patient-centred dietary intervention: an exploratory analysis. BMJ Open. 2014;4(6):e004953.

24. Trento M, Passera P, Bajardi M, et al. Lifestyle intervention by group care prevents deterioration of type II diabetes: a 4-year randomized controlled clinical trial. Diabetologia. 2002:45:1231-9.

25. Guidance on the use of patient education models for diabetes. Technology Appraisal 60.Guidance on the use of patient education models for diabetes. London: NICE; 2003

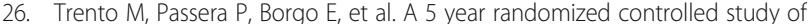
learning, problem solving ability, and quality of life modifications in people with type 2 diabetes managed by group care. Diabetes Care. 2004;27:670-5.

27. Rivellese AA, Boemi M, Cavalot F, et al. Dietary habits in type II diabetes mellitus: how is adherence to dietary recommendations? Eur J Clin Nutr. 2008;62:660.

28. CCM 2010. Progetto "Prevenzione dell' obesità in pazienti affetti da Diabete Mellito o Sindrome Metabolica attraverso un programma di Disease Management". www.ccm-network.it/progetto.jsp?id=node/1245\&idP=740.

29. Watson NA, Dyer KA, Buckley JD, Brinkworth GD, Coates AM, Parfitt G, Howe PR, Noakes M, Dye L, Chadwick H, Murphy KJ. A randomised trial comparing low-fat diets differing in carbohydrate and protein ratio, combined with regular moderate intensity exercise, on glycaemic control, cardiometabolic risk factors, food cravings, cognitive function and psychological wellbeing in adults with type 2 diabetes: Study protocol. Contemp Clin Trials. 2015;45(Pt B):217-25.

30. Aguiar EJ, Morgan PJ, Collins CE, Plotnikoff RC, Young MD, Callister R. The PULSE (prevention using LifeStyle education) trial protocol: a randomised controlled trial of a type 2 diabetes prevention programme for men. Contemp Clin Trials. 2014;39(1):132-44.

31. Salas-Salvado J, Bullo M, Babio N, et al. Reduction in the incidence of type 2 diabetes with the Mediterranean diet: results of the PREDIMED-Reus nutrition intervention randomized trial. Diabetes Care. 2011;34:14-9.

32. Salas-Salvadó J, Bulló M, Estruch R, Ros E, Covas MI, Ibarrola-Jurado N, Corella D, Arós F, Gómez-Gracia E, Ruiz-Gutiérrez V, Romaguera D, Lapetra J, Lamuela-Raventós RM, Serra-Majem L, Pintó X, Basora J, Muñoz MA, Sorlí JV, Martínez-González MA. Prevention of diabetes with Mediterranean diets: a subgroup analysis of a randomized trial. Ann Intern Med. 2014;160(1):1-10.

33. Via MA, Mechanick JI. Nutrition in type 2 diabetes and the metabolic syndrome. Med Clin North Am. 2016;100(6):1285-302.

34. Malik VS, Popkin BM, Bray GA, Despres JP, Willett WC, Hu FB. Sugarsweetened beverages and risk of metabolic syndrome and type 2 diabetes: a meta-analysis. Diabetes Care. 2010;33:247783.

35. Bray GA, Popkin BM. Dietary sugar and body weight: have we reached a crisis in the epidemic of obesity and diabetes?: health be damned! Pour on the sugar. Diabetes Care. 2014;37(4):950-6. 
36. Park S, McGuire LC, Galuska DA. Regional differences in sugar-sweetened beverage intake among US adults. J Acad Nutr Diet. 2015;115(12):19962002.

37. Morio B, Fardet A, Legrand P, Lecerf JM. Involvement of dietary saturated fats, from all sources or of dairy origin only, in insulin resistance and type 2 diabetes. Nutr Rev. 2016;74(1):33-47.

38. Ericson U, Hellstrand S, Brunkwall L, Schulz CA, Sonestedt E, Wallström P Gullberg B, Wirfält E, Orho-Melander M. Food sources of fat may clarify the inconsistent role of dietary fat intake for incidence of type 2 diabetes. Am J Clin Nutr. 2015;101(5):1065-80.

39. Pan A, Sun Q, Bernstein AM, et al. Red meat consumption and risk of type 2 diabetes: 3 cohorts of US adults and an updated metaanalysis. Am J Clin Nutr. 2011:94:1088-96.

40. Mendes R, Sousa N, Themudo-Barata J, Reis V. Impact of a communitybased exercise programme on physical fitness in middle-aged and older patients with type 2 diabetes. Gac Sanit. 2016;30(3):215-20.

41. Mathieu ME, Brochu M, Beliveau L. DiabetAction: changes in physical activity practice, fitness, and metabolic syndrome in type 2 diabetic and atrisk individuals. Clin J Sport Med. 2008;18:70-5.

42. Praet SF, Jonkers RA, Schep G, Stehouwer CD, Kuipers H, Keizer HA, van Loon LJ. Long-standing, insulin-treated type 2 diabetes patients with complications respond well to short-term resistance and interval exercise training. Eur J Endocrinol. 2008;158:163-72.

43. Osservatorio ARNO Diabete. II profilo assistenziale della popolazione con diabete. Rapporto. Bologna: CINECA 2015; 2015.

Ready to submit your research? Choose BMC and benefit from:

- fast, convenient online submission

- thorough peer review by experienced researchers in your field

- rapid publication on acceptance

- support for research data, including large and complex data types

- gold Open Access which fosters wider collaboration and increased citations

- maximum visibility for your research: over $100 \mathrm{M}$ website views per year

At $\mathrm{BMC}$, research is always in progress.

Learn more biomedcentral.com/submissions 